\title{
Cervical Ballistic Traumatism: A Case Report
}

\author{
Chafiki Z $Z^{*}$ Abou elfadl M, Rouadi S, Abada R, Roubal M and Mahtar M \\ Department of ENT, 20 Août hospital Ibn Rochd University Hospital, Casablanca, Morocco
}

*Corresponding author: Chafiki Z, Department of ENT, 20 Août hospital Ibn Rochd University Hospital, Casablanca, Morocco, E-mail: zakaria.chafiki@gmail.com

Citation: Chafiki Z, Abou elfadl M, Rouadi S, Abada R, Roubal M, et al. (2016) Cervical Ballistic Traumatism: A Case Report. J Case Rep Stud 4(6): 602. doi: 10.15744/2348-9820.4.602

Received Date: June 04, 2016 Accepted Date: December 27, 2016 Published Date: December 29, 2016

\begin{abstract}
The adequate care of cervical ballistic traumatisms implies a good preliminary knowledge of wounding agents, and of the principles governing lesion-based ballistic, in particular the role played by the meeting with an obstacle which modifies the ballistic behavior of the projectile, with worsened wounding effects. Authors describe the principal types of involved projectiles and their wound profile applied, while stressing the need to treat systematically the wound and not the weapon, and on the importance of the choice of the surgical exploration way of these lesions, which conditions, as from the initial stage, the later choices of the closure and rebuilding methods.
\end{abstract}

Keywords: Cervical injuries; Black powder rifle; Wounds and injuries

\section{Introduction}

Ballistic Traumatism is the consequence of penetration in the organism from a projectile: bullet, lead, metallic fragment coming from the envelope or from the contents of an explosive device (grenade, mine, shell, bomb...).

Cervico-facial ballistic traumatisms are not common in Morocco and they usually happened accidentally, their severity is variable, it depends on clinical impact, the site of the lesion and lesionnel mechanism. They always require a surgical procedure.

\section{Methods and Objectives}

The purpose of this paper is to bring back a new observation of Ballistic Traumatism caused by an explosion of a rifle with black powder and to describe their epidemiological, clinical, and therapeutic and prognosis characteristics.

\section{Clinical Case}

50 Years old male without pathological antecedents, was taken to the ENT emergency for haemorrhagic cervical submandibular wound caused by an explosion of a rifle with black powder during a fantasia. Clinical examination found a submandibular wound of $1 \mathrm{~cm}$ with a huge haematoma and active bleeding, without hemodynamics chok signs. Endo-buccal examination found a wound of the internal face of the cheek with a buccal floor wound which communicate with the contra lateral submandibular wound (Figure 1).

Surgical exploration was done under general anesthesia, and addressed the submandibular lodge (Figure 2): after aspiration of a large bruise was discovered a piece of $3 \mathrm{~cm}$ gun (Figure 3 ) in rat facial artery without reaches. Its ablation was performed without incidents; the cheek and floor of the mouth wound was sutured in one plane vicryl 4/0 round needle. The rest of the exploration was no anomaly with setting up a suction drain. The postoperative course was good without sequelae.

\section{Discussion}

Cervical ballistic trauma is defined as all injuries projectilaire of origin, open or closed. This is frequent and severe lesions characterized by multiple clinical presentation and frequency of associated lesions [1]. They involve life-threatening by blood loss, respiratory distress and associated lesions and secondarily by the risk of infection with a contamination immediately wound associated with attrition and a more or less extensive tissue devitalized by cavitation $[2,3]$. 


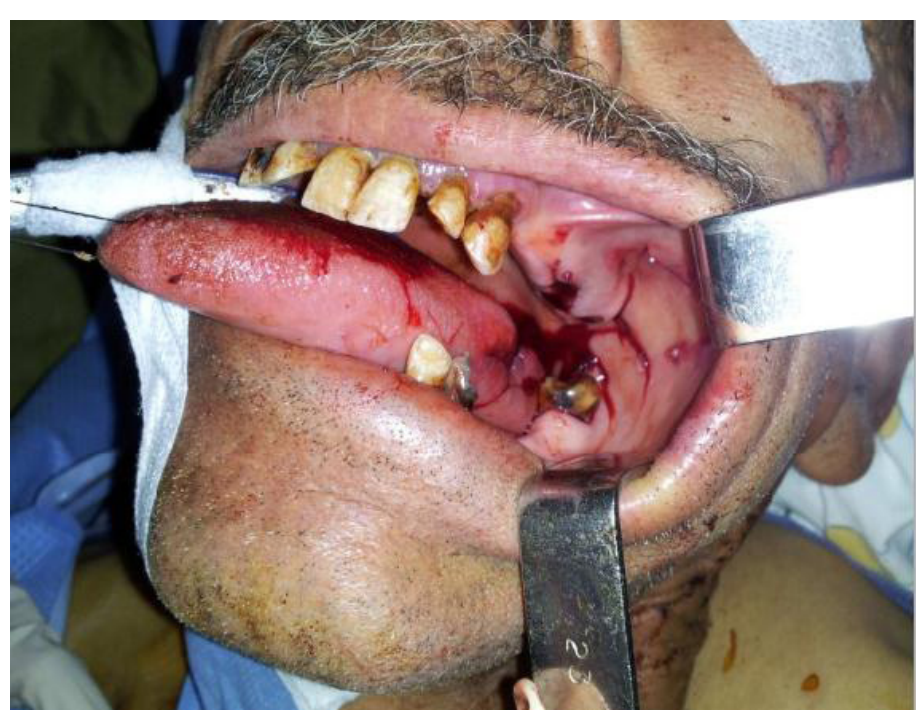

Figure 1: Wound of the inner face of the left cheek

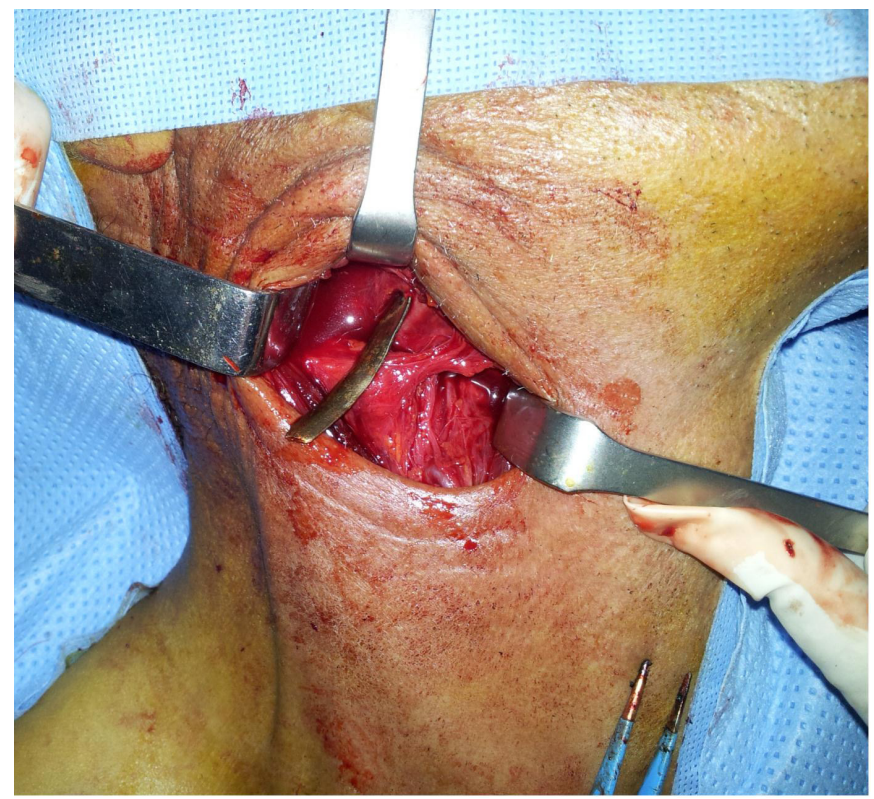

Figure 2: Piece of gun powder

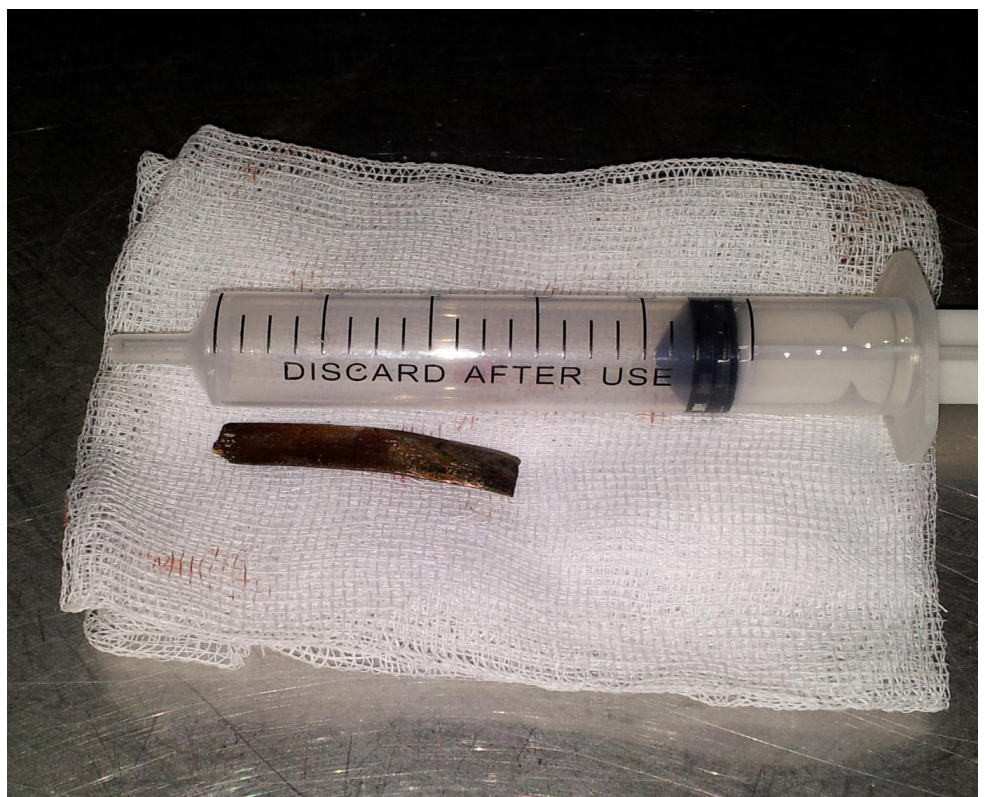

Figure 3: Piece of gun powder measuring $3 \mathrm{~cm}$ 
The wounding agents involved in the ballistic injuries are diverse and varied essentially represented by projectiles of 2 types: with a clear predominance of chips behind polycriblages and polyblessures and bullets from handguns or shoulder. A ballistic study of different wounding agents involved to understanding injury mechanisms encountered. Their multidisciplinary management has improved the survival and prognosis by advances in resuscitation, treatment, and modern imaging [4,5]. It sometimes requires urgent actions, intubation airway pending a possible cervicotomy or an endoscopy [1]. Crisis situations such terrorist acts or war further complicate this assumption by the variety of wounding agents encountered by the frequency of polycriblages and the risk of a massive influx of wounded. A good knowledge of wounding agents and their lesion with terminal ballistics profile is therefore a prerequisite for the appropriate management of these injuries [5,6].

\section{Conclusion}

A good knowledge of wounding agents and wound ballistics principles is essential to the management of cervical ballistic trauma, knowing that the lesion profile of a projectile may be amended at any time by meeting with an obstacle with deformation or fragmentation originally an aggravated wounding effect.

\section{References}

1. Sosa JL, Pombo H, Puente I, Sleeman D, Ginzburg E, et al. (1998) Thoracoscopy in the evaluation and management of thoracic trauma. Int Surg 83: 187-9.

2. Azorin J, Lamour A, Hoang Ph, Destable MD, De Saint Florent G (1987) Traumatismes graves du thorax In: Encycl Med Chir. Urgences, 24-117- D-10. Paris: Editions scientifiques et Médicales Elsevier SAS.

3. Jourdan PH, Jancovici R (1990) Traumatismes de guerre du thorax. J Chir 127: 68-75.

4. Fackler ML, Malinowski JA (1985) The wound profile: a visual method for quantifying gunshot wound components. J Trauma 25: 522-9.

5. Harvey EN, Korr IM, Oster G, Mc Millen JH (1946) Secondary damage in wounding due to pressure changes accompanying the passage of high velocity missiles. Surgery 21: 218-39.

6. Fackler ML, Surinchak JS, Malinowski JA, Bowen RE (1984) Bullet fragmentation: a major cause of tissue disruption. J Trauma $24: 35-9$.

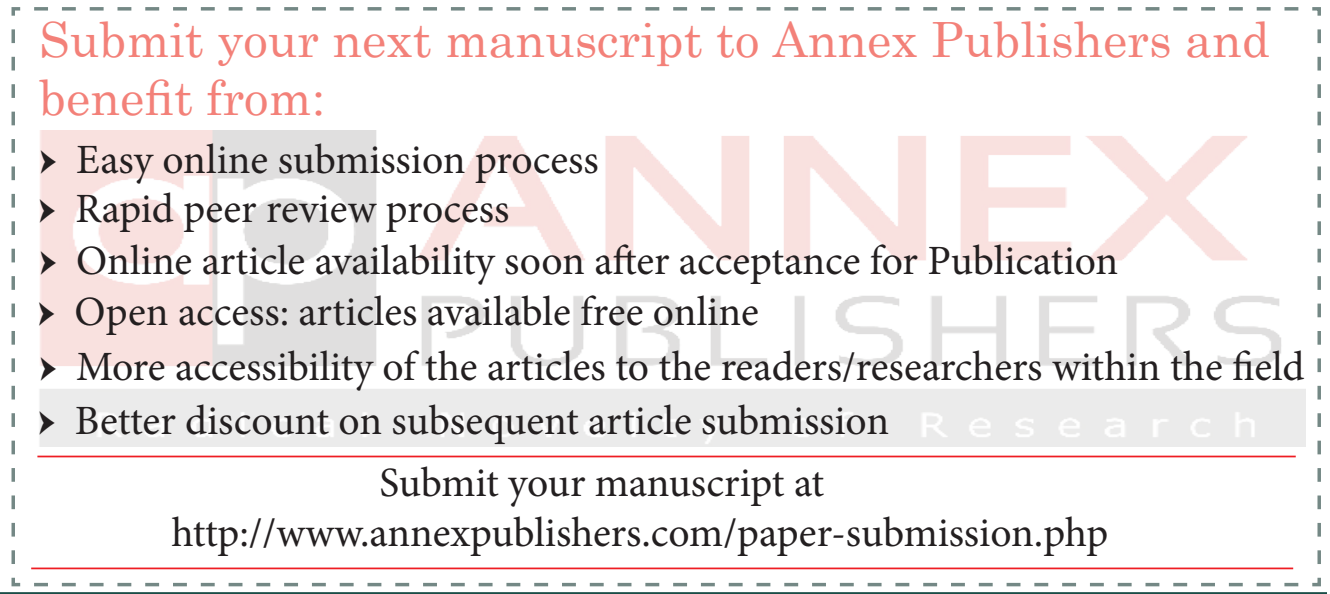

